\title{
Apuntes sobre la ritual expulsión del mal en la plaza pública y edición de El antojo de la gallega, mojiganga de Francisco de Castro
}

\begin{abstract}
[La] designación de matapecados o castigapecados cobra plena significación si, en los festivales de Carnaval $\multimap$ en los del Corpus con sus mascarones y figuronesle asignamos un papel en la ritual eliminación del mal, personificado por dragones, tarascas, Judas u otras mil metamorfosis de la víctima expiatoria ${ }^{1}$.
\end{abstract}

Sirva esta cita de punto de partida para tratar algunas de las "otras mil metamorfosis de la víctima expiatoria " celebradas en la plaza pública y recogidas en relaciones de fiestas y en piezas del teatro breve del siglo XVII. Valga también la mención de Judas en las ceremonias simbólicas que tratan de expulsar el mal para reflexionar en torno a la ambigüedad de estas figuras, que afecta incluso a la designación, aunque no es nuestra pretensión tratar aquí de forma exhaustiva el tema.

Ciñéndonos, pues, a este último personaje, el Sábado de Gloria tenía lugar la denominada "quema del Judas". Tratábase de un muñeco que representaba al apóstol traidor. Se recoge esta costumbre en el entremés El Judas a la fuerza, en el que "enjudan" al bobo Bras con un vestido, una peluca y un sombrero ridículos, y simulan quemarle encima de una rueda ${ }^{2}$. Existía la variante del tiroteo del personaje, y así sucede en Alosno al tiempo que los niños cantan los versos *judas murió, / Cristo resucitó!. Este monigote llevaba en una mano una bolsa con cáscaras de almejas, en recuerdo de las monedas por las que Judas vendió a Cristo ${ }^{3}$, y podía recibir el nombre de Mahoma. De hecho, los versos «Muera, muera Mahoma", cantados en la mojiganga dramática anónima El alma,

1 E. Asensio, Itinerario del entremés. Desde Lope de Rueda a Quiñones de Benavente (Madrid: Gredos, 1971), p. 22.

2 Se inserta la pieza en el ms. 14.770 BNM, ff. 165r-167v. J. Caro Baroja, El Camaval (Análisis bistórico-cultural) (Madrid: Taurus, 1965, reimpr. 1984, p. 143), nos informa también de la representación de la Pasión que se celebraba en Villanueva de la Serena hasta 1919. Concluía con la entrada de Judas, caracterizado con una barba y una peluca rojas, por un orificio practicado en el tablado, del que salía, simulando el infierno, una gran llamarada. Reaparecía luego Judas convertido en demonio, con otro atuendo.

3 Id., ibid., p. 142. 
posiblemente aludirían a esta costumbre ${ }^{4}$. Otra designación -la de "Antruido", propia de la montaña santanderina- se explica por el paseo por el pueblo de este pelele de trapo en la fiesta de antruido el martes de Carnaval ${ }^{5}$. Es decir, el muneco indicaba su traición a los principios cristianos y podía asociarse por ello a las fiestas de Carnaval, o bien por idéntico motivo se le daba muerte al tiempo que se celebraba la Resurrección de Cristo. Iba ligado, por tanto, a los ciclos de Carnaval y Semana Santa.

Otro tanto ocurre con la figura del turco, que curiosamente aparece en la plaza plública representando tanto a la Cuaresma como al Carnaval. Centrándonos, entonces, en la mojiganga dramática El antojo de la gallega, de Francisco de Castro, salen aquí cuatro turcos y el Rey de Marruecos, al que quitan, al son de la Marsellesa, cabezas, brazos y piernas ${ }^{6}$. El despedazamiento del Rey de Marruecos constituye una variante de la costumbre de "serrar" la vieja que simbolizaba la Cuaresma. En efecto, la Cuaresma se figuraba por medio de una anciana con siete piernas que, paulatinamente, se le iban cortando hasta que terminaban las siete semanas del período cuaresmal. Finalmente, el Sábado Santo y coincidiendo con la Resurrección, se la degollaba ${ }^{7}$. Conservamos dos mojigangas dra-

- Id., ibid., p. 140. Hoy la fiesta de moros y cristianos de Villena acaba con la destrucción de una gigantesca cabeza, denominada sla Mahoma. Los vecinos de este pueblo la consideran más cerca al rey del Carnaval que al profeta musulmán. Cf. S. Carrasco Urgorti, "La fiesta de moros y cristianos y la cuestión morisca en la España de los Austrias", Jornadas sobre el teatro popular en España (9-11 de diciembre de 1986), ed. de J. Álvarez Barrientos y A. Cea Gutiérrez (Madrid: CSIC, 1987), p. 83. Por otro lado, J. SuвIRÁ, -El villancico literario-musical. Bosquejo histórico, Revista de Literatura, XXIII (1962), p. 22, al analizar el villancico escénico, nota que, entre las piezas que cantan los personajes de Los vagabundos y ciegos fingidos, tonadilla escénica musicada hacia 1770, destaca el "Villancico a la muerte de Mahoma", que revienta por beber vino en exceso. Sobre la mojiganga El alma, véase C. Bufzo, La mojiganga dramática, (Madrid, Caja de Madrid: Ed. Reichenberger-Kasel, 1993).

J. Caro Baroja, El Camaval, p. 122.

"Aquí el Rey de Marruecos sustituye al Gran Turco, puesto que cuatro turcos lo acompanan. Ocurre a la inversa, lo que da idea de la intercambiabilidad de ambos, en la mojiganga de moros y cristianos que el platero Fermín Garro organizó durante las fiestas de Huesca con motivo del natalicio de Felipe Próspero. En la plaza de la Seo se concluyó la acometida de los cristianos contra el carro de los moros con la degollación de la figura del [Gran] Turco que se erigía en tal carro. Véase la Relación de las fiestas que la civdad de Huesca en el reymo de Aragón ha hecho al nacimiento del Príncipe nuestro Señor D. Felipe Próspero (1659). BNM V.E. 63/40. Del mismo modo, en los festejos que hizo Logroño por el nacimiento de los infantes gemelos Carlos y Felipe y por la paz firmada con Inglaterra, salió el 25 de noviembre de 1783, por la noche, un carro triunfal en forma de barco, con una terrible cabeza de turco en la proa. Le precedían ocho moros vestidos de cautivos, con grillete al pie. Véanse los Festejos de la Ciud d de Logroño al Nacim to de los dos Infantes Gemelos Carlos y Phelipe: y á la paz firmada con Inglaterra (1783). Cf. J. Alenda y MiRA, Relaciones de solemnidades y fiestas puiblicas en España (Madrid, 1903), núm. 2.154.

J. Caro Baroja, El Camaval, p. 136. 
máticas que recogen la tradición de los vecinos de Madrid de air a ver partir la vieja" en la Plaza Mayor ${ }^{8}$.

El aserramiento o quema de un ser imaginario se encuentra en muchos pueblos europeos y es, al parecer, el resto de una antigua ceremonia simbólica que trataba de expulsar el espíritu de la muerte fuera de la población. Así lo hace notar Joan Amades:

El serrament de la vella, així com la seva destrucció pel foc el Dissabte de Glòria. recorden la destrucció dels esperits malèvols i l'anorreament de l'hivern [...] En època cristiana, el serrament de la vella sembla significar la celebració de l'arribada a la meitad del temps d'abstinència i de dures privacions en el menjar [...] Ara, el serrar la vella significa, doncs, partir en dos trossos l'enutjosa Quaresma, per assenyalar l'arribada a la seva meitat".

La variante de la partición y posterior degollamiento del Rey de Marruecos o del Gran Turco representando la Cuaresma no es mencionada por Caro Baroja, quien sí alude, en cambio, a un romance que describe ciertas Carnestolendas madrileñas del siglo XVII, donde el Carnaval sale vestido a la turca, para indicar claramente su anfidelidad a la moral cristiana" ${ }^{10}$.

De lo anterior se desprende no sólo que el Carnaval se figuraba de diversas maneras, aunque era común su representación por medio de un personaje a horcajadas sobre una cuba de vino ${ }^{11}$, sino también que las anteriores manifestaciones del Carnaval y de la Cuaresma eran reflejo de la condena por parte de la religión católica tanto de los infieles como de los disidentes o traidores. Paralelamente, tenían lugar en la plaza pública actos de fe, que contemplaba la población como un espectáculo. La fiesta pública se llenaba así de connotaciones religiosas que servían para reforzar los dogmas del catolicismo (en las fiestas que Sevilla dedicó a la Purísima Concepción en 1617, ahorcaron por un pie a una figura grotescamente vestida, que simbolizaba en este caso el pecado original ${ }^{12}$ ). Y a la inversa, los juicios inquisitoriales se aproximaban a representaciones festivas. Véase como muestra el auto de fe con el que los estudiantes

8 Se trata de la pieza anónima Lo que pasa en mitad de la Cuaresma al partir la vieja, de aproximadamante 1630. que se encuentra en el ms. 46.721 BITB. y en el ms. 61.447 BITB, y de la mojiganga de Francisco de Castro titulada Ir a ver partir la vieja, incluida en Alegría cómica 1a. parte, Zaragoza, 1702, ff. 90-103.

9 J. Amades, Costumari catalá. El curs de l'any (Barcelona, 1951), II, pp. 649 y 654.

10 J. Caro Baroja, El Camaval, p.128.

$"$ A. Redondo, “Tradición carnavalesca y creación literaria. Del personaje de Sancho Panza al episodio de la Ínsula Barataria en el "Quijote", Bulletin Hispanique, LXXX, 1-2 (1978), p. 42.

12 Relatione del Pre. Gio. de Pineda della Compagnia di Giesus (sic), sopra la dimastrazione e festa fatta in Seutiglia nella riceunta del Decreto fatto da N.S. in materia della Conceptione della Madonna (1617). Cf. J. Al.fNDA Y MirA, Relaciones..., núm. 686. 
del colegio de San Ambrosio de la compañía de Jesús de Valladolid "amenizaron" en 1740 las fiestas de luminarias, fuegos, comedias, danzas, cabalgatas y mojigangas. Leemos:

\author{
Por mandado del Supremo \\ a un judío se quemó \\ por pertinaz y por terco ${ }^{13}$.
}

Así pues, los actos multitudinarios de carácter represivo y la fiesta barroca en su conjunto sirven para cohesionar las estructuras del poder, y el estudio de diversas ceremonias ligadas a la plaza pública -concretamente los ahorcamientos, degollaciones, aserramientos y tiroteos de muñecos-, así como de otros personajes dentro del campo semántico del infiel o renegado lo ponen de manifiesto ${ }^{14}$.

La mojiganga dramática El antojo de la gallega encierra varias mojigangas parateatrales: la del "mundi nuevo", que la gallega ve gracias al conjuro del estudiante, y la del baile de mojiganga final, que consiste en este caso en una danza de espadas. Se trata de un esquema frecuente en otras piezas del género: un tercer personaje (el estudiante mago) ayuda a A (la gallega embarazada que tiene el antojo de ver un "mundi nuevo") e indirectamente a B (el "golilla", encargado de las fiestas del Corpus) haciendo salir a todas las figuras de la mojiganga.

Por otro lado, la primera mojiganga se organiza al modo de las cajas chinas: un estudiante hace salir a un italiano con un "mundi nuevo", el cual, a su vez, contiene diversas figuras. La mojiganga del "mundi nuevo" es una mezcla abigarrada de varias danzas, como es usual en el género ${ }^{15}$ : la de los portugueses, la de los asturianos y la ejecutada al descuartizar

14 Nueva relación, y curioso romance, de la Función, que los Estudiantes de San Ambrosio de la Compañía de Jesús, con ocasión de celebrar la Obra de los Generales nuevos (... J bizieron en Valladolid el dia 22 de Diziembre de 1740. Cf. id., ibd., núm. 1.885.

"Incluso desfila San Pedro como renegado, enfatizándose este aspecto haciendo que formen comitiva burlesca junto a un cortejo de musulmanes slas negociaciones y lágrimas de San Pedro", personificadas. Véase A. Soons, "Un texto inédito sevillano de 1714, de tipo carnavalesco", Archivo Hispalense, 200 (1982), pp. 139-148.

is Asi lo documenta J. Sfatalirfns en "Bailes y entremeses en los escenarios teatrales sevillanos de los siglos vir y xvit: ¿géneros menores para un público popular?., en El teatro menor en España a partir del siglo xit, ed. de L. García Lorenzo (Madrid: CSIC, 1983), p. 73. Reproduce el siguiente testimonio relativo a las danzas del Corpus de Sevilla de 1640: -la mojiganga, bien vestida conforme al baile de la comedia, con doce figuras, y el que tañe el tamboril, y en ella ha de haber una cuadrilla de gitanos, otra de negros, con tamborilillos, otra de vizcainos, con espadas, como bailan en Vizcaya*. 
al Gran Turco. El mismo esquema se repite en las mojigangas dramáticas El mundi nuevo de Vicente Suárez de Deza, y en El mundi novi, de Francisco de Avellaneda ${ }^{16}$. Además, comparsas ridículas como la del séquito del Gran Turco o la de la danza de espadas con que se cierra la pieza eran en sí mismas mojigangas.

Las denominaciones "Tripahueca" y "la Corvilla" para el golilla y la gallega aparecen en boca de un italiano que enseña un "mundi novi. "Tripahueca" se opone a "San Pansart" o "Santo Panza", santo carnavalesco, y "la Corvilla" alude al "miércoles corvillo" o "miércoles de Ceniza", primer día de la Cuaresma. No hay que olvidar que las representaciones teatrales durante ese período se limitaban a las funciones de títeres ${ }^{17}$. El "aserramiento" del Gran Turco, vinculado al de la "vieja Cuaresma", era también, como vimos, un espéctaculo cuaresmal. De este modo, en $\mathrm{El}$ antojo de la gallega, que se representó durante el Corpus, se escenifican los preparativos para ejecutar una mojiganga parateatral para esa fecha (mojiganga final de los danzantes de espadas) y se incluye una mojiganga del "mundi nuevo" representada por un titiritero en tiempo de Cuaresma. Se produce, pues, como en el caso de la aparición del fariseo de la degollación de los inocentes en piezas para Corpus, el trasvase de un festejo de una época a otra ${ }^{18}$.

\section{NOTICIA BIBLIOGRÁFICA}

- Ms. 14.804 de la Biblioteca Nacional de Madrid, procedente de la de Osuna. Consta de 8 hojas y en la portada se lee: "Mojiganga para el auto de Calderón El tesoro escondido, que se representó en 1705". La Barrera (p. 607). Nota de A. Paz y Mélia (núm. 228): “De mano de José de Cañizares, aunque en la portada escribió el título Francisco de Castro, que afirma lo compuso en 1705 y de quien dice es autógrafo La Barrera. Son también autógrafas de Castro varias enmiendas al texton.

- Ms. 15.200 de la Biblioteca Nacional de Madrid, con letra del siglo XVIII. 6 hs. (Paz y Mélia, núm. 228).

16 El mundi nuevo (1662), de Vicente Suárez de Deza, se encuentra en el ms. 46.561 BITB., copia de Donaires de Tersicore, Madrid, 1663, y El mundi novi (1675), de Francisco de Avellaneda, se imprimió con la comedia El templo de Palas, Nápoles, 1675, f. 20.

J. E. VARFY, Historia de los títeres en España desde sus origenes hasta mediados del siglo xı'II (Madrid: Revista de Occidente, 1957), pp. 239-243. Escribe F. Porras, Titelles. Teatro popular (Madrid: Editora Nacional, 1981), p. 169: .De los datos que facilita Varey se ve claramente la cantidad extraordinaria de funciones de títeres y de volatines que se realizaban en Madrid durante la Cuaresma".

18 Véase C. Bıfzo, "El sacristán fariseo. Edición de un entremés inédito y apuntes sobre la figura del fariseo, Criticón, 50 (1990), pp. 93-112. 
- Ms. 61.540 de la Biblioteca del Instituto del Teatro de Barcelona, con letra del siglo XIX. 11 hs. Cpia de ms. autógrafo de la Biblioteca de Osuna. Notas de Cotarelo (Simón Palmer, núm. 1.176).

\section{Métrica}

Esta mojiganga dramática consta de 375 versos. Predomina el romance octosílabo de rima eo (vv. 1-137, 142-143, 148-239, 244-345), hay un final en seguidillas (vv. 346-375) y se incluyen otros versos cantados (hexasílabos de rima consonante aa-a: vv. 138-141, 144-147 y octosilabos de rima consonante -aaa: vv. 240-243).

\section{Catalina Buezo}

Es ésta una edición de la mojiganga autógrafa e inédita de Francisco de Castro que lleva por título El antojo de la gallega. La pieza tiene la peculiaridad de presentar en escena el despedazamiento del Gran Turco, que aparece aquí como una variante de la partición y aserramiento de la vieja que simbolizaba la Cuaresma. Se alude, asimismo, a otras degollaciones y ahorcamientos similares, no carentes de contenido ideológico, si bien entroncan con las rituales eliminaciones del mal en la plaza pública en tiempo de fiesta.

This is a edition of the autograph and unpublished "mojiganga" El antojo de la gallega, by Francisco de Castro. The Greak Turk is decapitated in a performance that appears as a variant of the beheading of Lent time, generally symbolized by a grotesque old woman. We also mention other throat cutting customs, that besides their ideological implications, are linked to the rituals of evil's destruction in the public square during holiday time. 


\section{Personas}

$\begin{array}{ll}\text { el estudiante } & \text { el golilla } \\ \text { la gallega } & \text { el a[l]guacil } \\ \text { el portugués } & \text { [la] portuguesa } \\ \text { italiano/dueña } & \text { el niño [gallego] } \\ \text { la niña [asturiana] } & \text { el [Gran] Turco } \\ \text { criados y danzantes } & \text { mujer } 1 .^{:} \\ \text {mujer 2." } & \text { mujer 3." }\end{array}$

Sale la gallega corriendo del golilla y estudiante.

GALLEGA.

ESTUDIANTE.

GOLILLA.

GALLEGA.

ESTUDIANTE.

GALLEGA.

GOLILLA.

GALLEGA.

GOLILLA.

GALLEGA.
¡Ay de mí, coitada!

$$
\text { Aguarda, }
$$

domina.

Di ¿con qué intento das esas voces? ¿Qué tienes? ¡Ay, ay, ay, malparir quiero! ¡Válgame Santu Dumingo de Guriyón, que revento! ¿No fuera por un ijar?

Déjenme fujir.

\section{Teneos}

y sepamos vuestro susto.

Escochadme, caballeros:

Anoite, en las Maravillas, llamaron un mundi nuevo, que me da la pataleta así que a nombrarlo llego. Sosiégate, por San Lesmes, $y$ prosigue.

Ya escompienzo:

para celebrar la boda de un fillo de Mondoñedo, mi paisano, había en él más de ducientos muñecos, que hacían dos mil diabruras. Yo me enamoré de verlos, $y$ así he venido a buscarlos otra vez, y a nadie encuentro, que me han dicho que se han ido 
y así quiero malparir, pues no logro mi deseo.

¡Ay que me aforquiño, ay que la paletilla al suelo

se me cae con los livianos!

¡Ay que rabio, ay que pateo!

Sale el alguacil.

ALGUACIL.

GOLILLA.

GALLEGA. ESTUDIANTE.

ALGUACIL.

ESTUDIANTE.

GALLEGA.

TODOS.

GOLILLA.

ALGUACIL.

GALLEGA.

ESTUDIANTE.

AlgUACIL. ESTUDIANTE.

GOLILLA.

¿Qué ruido es este en la calle?

Vengan al instante presos.

Señor, aquesta mujer

lo causa, pues con extremos

viene dando dos mil gritos

$\mathrm{y}$, su motivo inquiriendo,

nos dice que es un antojo

el cual no tiene remedio.

Esto es todo lo que pasa.

¡Ay, ay, ay!

¡Voto a San Peco!

Siendo así yo los perdono, porque, aunque hombres, no sabemos en qué nos podremos ver.

Si saben guardar secreto, yo me atrevía a hacer que se le cumplan sus deseos de aquesta mujer.

¡Coitada

de mí! ¡Santa Croiz de o ferro!

Esto es castigarme porque no vos cumplí el juramento. Mire osté que se resbala, que se escurre.

Deteneos.

Pues yo prometo callar. $\mathrm{Y}$ yo también lo prometo. ¿esús, que me despilfarro! Mire vosté que revento. Pues en fee de lo propuesto, les digo a ustedes que yo soy grandísimo hechicero, $y$, si quiero, haré venir por esos aires... ¡San Diego!

A todo el infierno junto con mi conjuro.

¡Ahí va eso! 


Pues amigo, yo me voy
a mi casa, porque tengo
que prevenir dos mil cosas
que conduzcan al obsequio
de las fiestas del Señor,
como me hallo sin remedio
prioste aqueste año de ellas
en esa villa de Meco,
y así, porque hago falta.

ALGUACIL.

Yo he de hacer un prendimiento

ESTUDIANTE. y voy a la ejecución.

Ya os entiendo, ya os entiendo.

¿Queréis escaparos? Nones.

¿A delatar de mí? Nego.

No me obliguéis a que haga

que luego esos firmamentos

se vengan abajo.

GALLEGA.

GOLILLA.

¡Zape!

Me conformo.

Me convengo.

ESTUDIANTE.

Veréis diferentes piezas

de diversión y gracejo.

GALLEGA.

GOLILLA.

Mire vosté que malparo.

Vamos a mi casa luego.

\section{Vanse.}

Y tú, gallega o demonio,

síguenos.

ESTUDIANTE.

Pero te advierto

que no digas lo que vieres.

GALLEGA.

Yo no más que a todo el pueblo.

Salen las tres mujeres.

[MUJER] 2. ${ }^{\mathrm{a}}$

En hora buena, doña Alda, del Señor en los festejos te emplees.

MUJER $3 .^{a}$

En hora buena

goces el dichoso empleo

de priosta dos mil años

en vida de don Anselmo,

tu pariente.

MUJER $1 .^{a}$

En hora buena

recibo, con gusto inmenso, vuestros parabienes, hija.

MUJER $2 .^{2}$

La mujer es un portento. 
Dentro.

GOLILLA.

MUJER $1 .^{\mathrm{a}}$

GOLILLA.

MUJER $10^{\mathrm{a}}$

LAS DOS.

GOLILLA.

MUJER $3 .^{\prime \prime}$

MUJER $2: "$

GOLILLA.

MUJER $1 .{ }^{\prime \prime}$
¡Ah de casa!

$$
\text { ¡Mi marido! }
$$

Abran esta puerta presto.

Ya voy, hijo. Mas ¿qué tienes

que vienes tan macilento?

105

Sale como asustado el golilla.

No traigo nada. $\mathrm{Haz}$ al punto

desocupar... Mas ¿qué veo?

Perdonad, señoras, que

no os había visto ([Ap.] ¡Estoy muerto!)

en la sala.

Con nosotras

110

no es menester cumplimientos.

Que viene aquí una gallega

que, antojada de buñuelos,

sin haberlos en mi casa

viene a cumplir sus deseos;

115

y así a hacer dos mil diabluras

el estudiante Berrueco

con ella viene, ninguna

se asuste.

$\mathrm{Y}$ yo también.

Yo verlo quiero.

Entren todos.

Hijo, mira que te advierto

que los danzantes han dicho

que todos estarán luego

a darte la muestra.

\section{Salen todos.}

GOLILLA.

Vengan

¿No entran ustedes? ¿Qué es esto?

ESTUDIANTE.

Señoras, buenas auroras.

MUJER $1 .^{a}$

Bienvenidos, caballeros.

Estoy al aquél de ustedes.

Me alegro de veros bueno.

Mire vosté que malparo.

130

Calla, diablo del infierno.

¡Jesús, qué horrible tarasca!

Cierren esa puerta presto,

porque voy a hacer mi oficio,

$y$, pues ya informado vengo
MUJER 1:"

ESTUDIANTE. 
de las piezas que agradaron más a esta gallega, empiezo.

Canta.

Númenes diabólicos, genios zurumbáticos, las fúnebres cláusulas oíd de mi cántico.

Truenos.

ALGUACIL. GOLILLA.

ESTUDIANTE.

UNO.

ESTUDIANTE.
¡Ya las paredes se arruinan! ¡Ya todo se viene al suelo!

\section{Canta.}

Muñequillos mínimos, muñequillos párvulos, salid de la insípida caverna muy lánguidos.

Representa.

¿No obedecéis a mis voces?

\section{Dentro.}

Sí, señor, ya obedecemos.

Pues salga un italiano,

$y$ con primor haga un juego de manos.

Sale uno de italiano y por detrás de dueña, y bará lo que dirán los versos, y saca una mesa $y$ recado de jugar de manos, y la mesa se abre por en medio $y$ encima en cada esquina estará con dos abujeros por donde dos niños sacan la cabeza, uno de gallego $y$ otro de asturiana.

ITALIANO.

GOLILLA.

[MUJER] 2.

GALLEGA.

ESTUDIANTE.
Patrón, bon chorno.

¡Válgame San Nicudemus! ¡Ay Jesús, que me desmayo! Este vi en el mundi nuevo, aunque era más piquinino. No tomen susto de verlo, y prosiga y hágase corro, 
ITALIANO.

GOLILLA.

ALGUACIL.

ITALIANO.

GOLILLA.

ESTUDIANTE.

GOLILLA.

ALGUACIL.

GOLILLA.

ALGUACIL.

ITALIANO.

GOLILLA.

ALGUACIL.

GALLEGA.

ESTUDIANTE.

ALGUACIL.

GOLILLA.

ITALIANO.

GALLEGA.

GOLILLA.

ITALIANO.

GOLILLA.

ITALIANO.

GOLILLA.

ITALIANO.

GALIEGA.

ITALIANO.

GALLEGA.

ITALIANO. empieza y haya silencio.

Venite qua, qua venite.

160

¿Benito? Me llamo Anselmo.

¿Qué dice, si vendo agua?

No entender niente.

Esto es hecho.

Dice que os lleguéis allá.

Si ello ha de ser, obedezco.

Obedezco si ha de ser.

Pero, amigo, no burlemos.

¿Qué mandáis?

¿Qué me ordenáis?

Que, para hacer este juego

de manos, de lazarilles

me sirváis.

Fuera capas.

Ya yo estoy puesto.

Yo quisiera

ser la lazarilla o luego

aquí malparo.

Ea, señores, en esto

se le ha de dar también gusto.

Yo me zafo.

$\mathrm{Y}$ yo me quedo.

Plantache questi bonete

y vos estotro al momento.

¿No parezco encorvada?

180

¿Quién me metió en este enredo?

Fuerza es aguantar la mecha.

Ahora bien, empiezo el juego.

¿Cómo se llama vosté?

Yo me llamo don Anselmo.

185

Pues ahora se ha de llamar

Tripagüeca.

¿Y vos?

¡Vive el cielo!

Yo me chamo... aguarde,

que no sé si me recuerdo

...Dominga de Guriyón.

190

Pues que se llame ahora quiero

la Corvilla.

Va ipardiobre!

Señores, tengan chillencho.

Estes son tres pelotilles, las cuales pongo aquí en medio.

Tómate la una. 
Va la gallega a tomarla y le da con la vara en los dedos.

GALLEGA.

TODOS.

ITALIANO.

GOLILLA.
ITALIANO.

¡Ay mi mano,

mal diabro te afogue! Es juego;

la varita es de virtud, non pille fastidio de eso.

Calla, simple, que esto es chanza.

200

Toma tú estotra.

Flamenco,

mira que no gasto burlas.

¿Con qué así?

Va a tomarla el golilla y le da.

GALLEGA.

GOLILLA.

ESTUDIANTE.

GOLILLA.

ESTUDIANTE.
Toma buñuelos.

Oyes, finflón de los diablos, ¿a mí también? ipor San Peco que te he de matar! ipor vida...! Sosiégate, don Anselmo, ¿no ves que es juego de manos? No ha sido sino de dedos, $y$ he de hacer...

$$
\text { ¡Ah, Celestina! }
$$

Asusta a este majadero.

Vuélvese el italiano de dueña por detrás de que viene vestido, babla como tal.

\author{
ITALIANO. \\ MUJER $1 .^{\mathrm{a}}$ \\ MUJER $2{ }^{\text {a }}$ \\ GALLEGA. \\ GOLILLA.
}

ITALIANO.

GOLLLA.

ITALIANO.

GOLILLA.

MUJER $3 .^{2}$
¿Qué es aquesto, picarillo?

¿Hay tan grande atrevimiento?

¡San Cosme, que me da el flato!

¡Ay qué visión!

Cepos quedos.

Señora, soy un borracho, un hablador sin respeto, que no sé lo que me digo.

Pues, por vida de mi abuelo, que, si vuelves a enfadarme,

que os envie a los infiernos

a que cenes una migas.

¿Con quién?

$$
\text { Con Pedro Botero. }
$$

Yo lo estimo.

$$
\begin{aligned}
& \text { ¿No hay quien traiga } \\
& \text { quien conjure este aposento? }
\end{aligned}
$$


ESTUDIANTE.

ITALIANO.

TODOS.

GALLEGA.

ITALIANO.
Ya se acabó, Celestina.

Basta estar tú de por medeo.

Vamos al juego de manos.

Vuélvese el italiano al segundo verso.

¡Ay qué susto!

¡Doite au demo!

Tómate esta pelotilla,

y tú estotra, y ahora adentro

las tirad. De ellas, decidme:

¿qué queréis que salga?

Tira cada uno su pelotilla.

GALLEGA.

ITALIANO.

GOLILLA.

Según eso,

un portugués con guitarra.

¿Y tú, Tripe?

yo quiero una portuguesa.

ITALIANO.

Queiro

Obedeced los preceptos

de Tripagüeca y Corvilla;

salgan y hagan algo bueno.

Sale una mujer de portugués $y$ otra de portuguesa y cantan y bailan.

Salen los dos y cantan.

[LOS DOS]

ALGUACIL.

MUJER 3."

[MUJER] $1 . "$

ITALIANO.

Maricota de San Payo

come rata con tocino,

$y$, en chegando lo domino,

ya non poso beber vino.

Bailan como unos demonios.

Linda cosa.

Ya me alegro.

De esta pelotilla ancora

fato dos $y$, al mismo tiempo,

dos cabezas de muchachos

de los cubiletes mesmos

saco.

Sacan por las esquinas de la mesa las cabezas.

ALGUACIL.

[MUJER] $1 . *$

¡Válgame San Dimas!

GALLEGA.

Hoy aquí anda el diablo suelto.

¡Ay qué bonitos que son! 
ITALIANO.

Sóplate, gallega, luego

este cubilete, y vos

sóplate esotro.

Soplan los dos y se llenan el golilla y la gallega de tizne y harina.

[MUJER] 1.:

GALLEGA

GOLILLA.

ITALIANO.

LOS DOS.

ESTUDIANTE.

ITALIANO.
¿Qué veo?

Esta es una desvergüenza.

¿Con mi marido estos juegos?

¿No parece chimenea?

¡Por vida!

Vuélvese de dueña.

$$
\text { ¿Como valso }
$$

me provocan otra vez?

¡Quién estuviera en Marruecos!

¡Que los haré mil pedazos!

No callan ¿eh?

Callaremos.

Sosiégate, Celestina.

Por ti sólo me sosiego.

265

No pillen pavura, vengan.

Vuélvese de italiano.

TODOS.

ITALIANO.
Pues ¿quién sois?

El extranjero,

y ancora aquestas cabezas

al proviso tomen cuerpo.

255

\author{
260
}


TODOS.

ESTUDIANTE.

GALLEGA.

LOS NIÑOS.

ESTUDIANTE.

NIÑO.

GALLEGA.
¡Ay, Jesús, que se requiebran!

Di, gallega ¿quién son estos?

Aquesti es Juan de las Viñas

y Mariquita.

Empecemos.

Bailen la gaita gallega.

$\mathrm{Ea}$, miña alma, ballemos.

Ellos son mis paisanos

y quiero ballar con ellos.

285

Bailan, $y$ al fin se entromete la gallega y baila.

ESTUDIANTE.

ITALIANO.

Basta, vamos a otra cosa.

Pues salga el Rey de Marruecos

en acto de desnudarse

a la usanza de su reino.

Tocan instrumentos y salen de turcos y, detrás, el Rey.

TURCO.

[MUJER] $2 .^{a}$

[MUJER] $1 .^{a}$

GALLEGA.

GOLILLA.

[MUJER] $10^{a}$

ITALIANO.

[MUJER] $3 .^{*}$

ESTUDIANTE.

GALLEGA.

Yo me entro a mi gabinete

a descansar, porque vengo

fatigado del camino,

donde, a usanza de mi pueblo,

quiero que me desnudéis

para acostarme al momento,

y verán que soy de piezas

aunque me miran entero.

Señora, aquí anda el diablo.

$\mathrm{Y}$ el demonio, que es lo mesmo.

¡Doite a demo, qué barbazas!

¿Quién me ha metido a mí en esto?

En mi alcoba se ha campado.

No pillen fastido de esto.

iQue traigan agua bendita

y sahumarla con romero!

Ea, señoras, apartar.

Todo esto es del mundi nuevo.

\section{Dentro.}

TURCO.

¡Fámulos, a desnudarme!

Descübrese con este verso.

TURCOS.

Ya, señor, te obedecemos.

ESTUDIANTE. 
Corren una cortina y se ve sentado al Turco y, al son de la Marsella, le van quitando lo que dicen los versos, $y$ otros con bandejas van recibiéndolo $y$ se bacen algunas plantas ejecutando lo que dicen los versos.

TURCO.

[MUJER] $1 .^{\mathrm{a}}$

TURCO.

[MUJER] 2.a

TURCO.

[MUJER] 3.a

TURCO.

GALLEGA.

TURCO.

GALLEGA.

GOLILLA.

[MUJER] $10^{a}$

[MUJER] 2.a

[MUJER] $1 .^{\mathrm{a}}$

GALLEGA.

ESTUDIANTE.

DANZANTES.

GOLILLA.

[DANZANTE] 1.

LOS TRES.

[DANZANTE] 1.

TODOS.
Tiradme de aquesta manga.

¡El brazo le quitó entero!

Ahora tiradme de estotra.

¡Del otro han hecho lo mesmo!

Al punto idme descalzando.

¡Una pierna le han deshecho!

¿No dije que era de piezas?

Descalzadme estotro presto.

¡Todo le han despilfarrado!

320

Pues que sabéis que no duermo

con cabeza ¿qué aguardáis?

Arrancádmela al momento.

Quitanle la cabeza.

Si se la quitan, malparo.

¡Jesús, que sólo el pescuezo

le han dejado!

¡Que me asusto!

¡Qué congoja!

¡Que me muero!

Señores, que se resbala.

No se asusten, que es supuesto, y así...

Dentro.

Abran estas puertas,

que al Seor Prioste queremos

dar la muestra de la danza

que se ha de ir mañana a Meco.

Entren y hagan dos mudanzas.

Salen cuatro danzantes.

Con las espadas haremos
Con cuidado.

Empieza, Pedro.

¡A la salud del prioste!

Hacen unas mudanzas con espadas y dagas negras. 
GOI.ILLA.

ESTUDIANTE.

TODOS.

ESTUDIANTE.
Ea, bueno está lo bueno.

Acabe todo esto en broma

y los sustos volaverunt,

$y$, pues es día de Corpus, todos saquen instrumentos y acabe esta mojiganga. Norabuena.

Ea, empecemos.

\section{Canta.}

[MUJER] $1 . "$

Resuenen las sonajas

y los panderos,

trocando las tristezas

por los obsequios.

$\mathrm{Y}$ así bailen, que en Corpus

todo lo alegra

el panderillo, la tonadilla,

la sonajilla, la castañeta,

y, al compás de los gritos, arpa y vigüela.

\section{Canta.}

[MUJER] $2 . "$

Gallega antojadiza, con esa cara

tienes lo más andado

para tarasca.

$Y$ así baila que en Corpus

todo lo alegra

el panderillo, la tonadilla,

la sonajilla, la castañeta

$y$, al compás de los gritos,

arpa y vigüela.

\section{Canta.}

[MUJER] 3." todo lo alegra

el panderillo, la tonadilla,

la sonajilla, la castañeta,

y, al compás de los gritos,

arpa $\mathrm{y}$ vigüela. 


\section{NOTAS AL TEXTO}

- Se menciona, junto a las dramatis personae, a los siguientes actores en el ms. 61.540 BITB (C): Diego Rodríguez (una gallega). Teresa de Robles (un estudiante), Francisco de Castro (un golilla), Sra. Antonia Montiel (un portugués), Vicente Camacho (un niño gallego), Antonio Ruiz (un italiano), Gamarra (un alguacil), Sra. Paula de Olmedo (mujer 1."), Sra. Beatriz Rodríguez (mujer 2."), Sra. Isabel de Castro (una portuguesa), la hija de Gamarra (una niña asturiana), Ignacio de Figueroa (el Gran Turco), Fernando, Bartolo, Juan Álvarez y José vela (cuatro danzantes). No se especifica quién representó el papel de la "Mujer 3.". En el ms. autógrafo 14.804 BNM (A) se lee, después de concluir la pieza (ff. 9r-9v): El estudiante, Francisco de Castro (tachado y escrito al lado -Teresa de Roblesw); el golilla, Juan (tachado y sustituido por "Franciscon) de Castro; la gallega, Diego Rodríguez; el alguacil, Gamarra; el portugués, Antonia Montiel; portuguesa, Isabel de Castro; italiano/dueña, Antonio Ruiz; el niño, Vicente Camacho; la niña, la hija de Gamarra; el turco, Ignacio de Figueroa (tachado y reemplazado por "Fernando"); criados y danzantes, Fernando. Bartolo, Juan Álvarez y Joseph Vela; mujer 1.", Sra. Teresa de Robles (tachado); mujer 2.' (corregido: "1." Olmedo: mujer 3." (corregido: "2. ${ }^{3}$ ), Sra. Beatriz Rodríguez. Fs decir, hubo cambios en el reparto de papeles, aunque Francisco de Castro no los especificó todos. Así. si "Fernandow hizo) de Gran Turco en sustitución de Ignacio de Figueroa, un actor cuyo nombre no se constata, haría de criado/danzante. Por otro lado, el autor parece haber eliminado el papel de la umujer 3a.n, hecho que se aprecia en el elenco de actores y en las enmiendas al ms. autógrafo, que señalamos en las notas. Sin embargo, al final de la mojiganga Castro no corrige el texto -

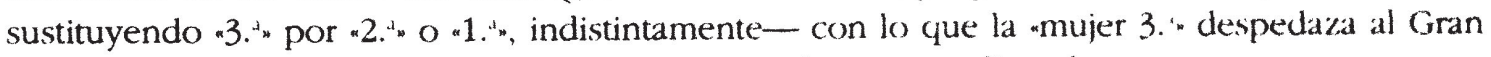
Turco y canta al fin. El ms. 15.200 BNM (B) no da ninguna lista de actores.

Hay que notar que ciertos personajes masculinos (el estudiante, la gallega y el portugués) fueron interpretados por mujeres, lo que concuerda con el "mundo al revés" carnavalesco que ofrece toda mojiganga. Por otra parte, la actriz Teresa de Robles debía de estar especializada en representar papeles masculinos, ya que en otras moigangas aparece como alcalde rústico ( cf. C. B' '́zo, La mojiganga dramática...). Finalmente, nótese que Francisco de Castro, autor de la pieza y actor, hace el papel de gracioso, término que en esta composicion dieciochesca ha sido sustituido por el de rgolillam.

* B: del estudiante; C: tachado y el y escrito supra del.

4. B: queiro; C: tachado quiero y escrito supra: queiro.

6-9. B y C reproducen totalmente estos versos, que en A se encuentran entre llaves. Santo Domingo de Guriyón es obviamente un santo burlesco. Para el empleo del santoral con propósitos cómicos, véase A. IGi isias Oifirko, alconicidad y parodia: los santos del panteón burlesco en la literatura clásica y el folklorem, Criticón, 20 (1982), pp. 5-83. Abundan este tipo de alusiones a lo largo de la composición. Más adelante se invoca a San Lesmes (v. 15), San Peco (v. 42), a la santa Croiz de o ferro* (v. 50), a San Diego (v. 63), a San Nicodemus (v. 154), a Jesús (v. 57 , v. 155 , v. 279, v. 326), a San Cosme (v. 215) y a San Dimas (v. 251). Por otro lado, en cuanto a la comprensión de los versos $?$ y ss.. le pregunta el estudiante a la gallega si su desasosiego se debe a un dolor de ijar o ijada ("cualquiera de las dos cavidades simétricamente colocadas entre las costillas falsas y los huesos de las caderas. DRAF).

10. B: Escochayme, caualeros.

13-16. Entre corchetes en $\mathrm{A}$ y en C.

14. A: Se ha tachado llego y se ha escrito supra: chego. B: escopienzo.

21. C: diabluras.

22. B: enamorey.

25-26. Entre llaves en A. B: $y$ me. 
27. B: queiro.

28. B: pois non logro meu deseyo.

29. aforcar es forma antigua del verbo *ahorcar.

31. livianos: "pulmones" (DRAE). B: livianus.

32. B: pateu.

37. C: escrito supra.: dos.

47. B: atrevo.

48. A: tachado sus y sustituido por los; B: se le cumplan sus deseos / a esta mujer; C: tachado: se cumpliesen los deseos / de aquesta mujer, y escrito supra.: se le cumplan sus deseos / a mujer.

49-60. Entre corchetes en A.

59-60. Entre llaves en C. B: isto; fe.

61-79. Presentación del estudiante hechicero o mago, que teme que el alguacil lo delate a la Inquisición. Sobre este personaje, véanse S. Waxman, "Chapters on Magic in Spanish Literature», Revue Hispanique (1916), III, 325-463 y C. Buezo, La mojiganga dramática..., ibid.

66. En A se ha escrito infra.: yo tengo un poco que bacer.

66-74. B reproduce estos versos, entre llaves en A y en C, donde están, además, tachados. Enmendamos a Dios [sicl por adiós.

88-91. Versos omitidos en B. Se reproducen entre corchetes en C (junto a vv. 86-87) y van tachados y entre llaves en $\mathbf{A}$.

- Tachado tres y corregido dos en A.

93-94. Versos tachados y en un recuadro en A; se omiten en B. Comienza aquí la segunda escena, en casa de la mujer del golilla, antes de la llegada de éste y de los personajes que han aparecido en la escena primera.

96. La mujer del golilla es priosta de las fiestas del Corpus, creación analógica a partir de prioste ("mayordomo de una hermandad o cofradía", DRAE).

100. A: tachado vuestros y escrito esos; tachada la -s de bijas.

108. A: tachada la $-s$ de señora.

110. A: esta sala [sic]; tachado con nosotras, sustituido por para mi.

113-114. B los elimina y A y C los ponen entre llaves.

115. A tacha los términos subrayados: "viene a cumplir sus deseos".

117. berrueco: "tumorcillo que se cría en el iris de los ojos, muy incómodo y de difícil cura. (DRAE). Nombre, pues, caracterizador y burlesco, como el de la gallega („Dominga de Guriyón., v. 190).

121-124. En A y C van entre corchetes los siguientes versos.

128-129. En recuadro en $\mathrm{A}$ y C.

131-132. Entre llaves en A y C.

150. C: supra: aqui.

151. C: tachado lue y supra: un.

- C: agujeros y otra. El juego de manos del titiritero se diferencia del conjuro infernal, aunque de tipo burlesco, en versos esdrújulos, del estudiante hechicero (vv. 138-141 y 144 147). El primero es representante de la magia blanca y el segundo de la negra, tipos que diferencia el doctor de la cueva de Salamanca de Ruiz de Alarcón. Cf. J. Álvarez Barrientos, La comedia de magia. Estudio de su estructura y recepción popular (Madrid: Universidad Complutense, 1986), pp. 10 y ss. La realidad bifronte del Carnaval explica el que este personaje 
por delante vaya disfrazado de italiano y por detrás de dueña. Ocurre otro tanto en mojigangas como La encantada, de Suárez de Deza, donde dos hombres aparecen vestidos por delante de tigres y por detrás de dueñas. Cf. C. Büzo, La mojiganga dramática...

156-159. Entre llaves en A y C.

163. C: enterder.

164-167. En A y C están entre paréntesis. En B y C se sustituye becho por bueno.

170. B: lazarillos.

173-174. Se omiten en B y se tachan en A y C.

176. A: en esto [sic] se le ba de dar también gusto.

177. C: safo.

178. C: güesti.

181. C: supra: este.

182-183. Entre corchetes en A y C.

187. C: Tripabueca.

188. B: ¿E vous?

193. B: chilencho.

194. B: pelotiles.

- B: a tomar la pelotilla; A: supra: vara.

198-199. A. y C: entre llaves.

204. finflón: nuevamente se recuerdan las conexiones del estudiante mago con el diablo, ahora con un apelativo despectivo. A y $\mathrm{C}$ : entre corchetes.

210. "Celestina. es el nombre que recibe el italiano cuando se vuelve y va vestido de dueña. A las dueñas se las acusaba de brujas y se solía resaltar su fealdad e hipocresía. Aquí se repiten estos rasgos, y lo mismo sucede en la mojiganga las beatas, de Antonio de Barrientos. Cf. C. Btiezo, La mojiganga dramática...

214-215. A y C: entre llaves.

221. A y C: tachado os y escrito supra: te.

224. A: corregido MUJER $2 .^{2}$

229. B: doite a o demo.

233. C: quiero.

237. B: los preced [sicl.

238. C: Tripabueca.

242. B: domiño.

243. B: viño.

244. Acerca del carácter demoníaco, sensorial, de la música en el teatro breve, y en concreto de la mojiganga, que se ubica esplícita o implícitamente en el infierno (se menciona a Pedro Botero en el v. 223, que reaparece en los infiernos en la mojiganga Las bodas de Proserpina), véase C. Buezo, La mojiganga dramática...

245. C: MUJER 3. ${ }^{2}$

253. A: tachado luego y escrito recio.

259. Se conserva la forma valse en Hispanoamérica, por lo que no sería extraño el sustantivo valso, asimismo masculino, si bien ha prevalecido el término vals.

261-262. A y C: entre corchetes.

269. al proviso: al instante. (DRAE). 
271. B y C: bailemos.

283. B: miñalma.

278-281. A y C: entre llaves. B y C: Aquesti. Juan de las Viñas era un títere de guante, y así lo documenta J. E. VARFY (Historia de los títeres..., p. 218).

283. B: bailemus; C: bailemos.

284-285. B: "pus quellos son mis paisanus / eu quero ballar con ellos".

290. A: tachado gabinete y escrito retrete.

299-304. En A tachados, y en $\mathrm{C}$ tachados y entre corchetes.

304. A: corregido [MUJER] 2." Este verso y el siguiente se omiten en B.

305-307. A, B y C: tachados y escrito supra: $y$ den aqui un sabumerio. En A se ha sustituido sabumarla por sabumamos.

* C: Entrese en lugar de Descúbrese.

- B: del Marsella. La Marsellesa debió de ser un son popular a principios del siglo xvin. Por su descripción en la mojiganga Los oficios, de Antonio de Zamora, se iniciaba con este tañido una especie de danza de espadas, que aquí ejecutarían los turcos. $C f$. C. Bıfzo, El sacristán fariseo..., p. 100-101, n. 29.

- C: deshacen.

316. C: dezcalzando.

320. C: tudo; C: lo.

- C: Quitalen.

325. C: pezcuezo.

330. Comienza la escena 3." con la entrada de los danzantes que al día siguiente irán a Meco. Esta representación la víspera del Corpus ante el alcalde responde a la "muestra" que tradicionalmente se daba ante las autoridades locales antes de llevar un baile de mojiganga a un lugar determinado, en este caso a Mecu.

338. C: Ala.

34()-341. A y C: tachados.

346. En A tachados, en B suprimidos y en $\mathrm{C}$ tachados y en un recuadro estos versos, que se sustituyen al margen por los siguientes: "Suene el pandero / y ande la chanza, / que este día, este día 'todo es de gracia.

306-365. Versos tachados en A y C y sustituidos por el estribillo comentado en la nota anterior; v. $360 \mathrm{C}$ : bailen.

366-369. Mención de los reyes Felipe V y María Luisa. Sobre la laudatoria final de muchas mojigangas, véase M. L. Lomalo, "Mojigangas parateatrales y teatrales en la Corte de Carlos II (1681-1700)", en El teatro español a partir del siglo xir. Historia, cultura y teatro en la España de' Carlos II (Amsterdam: Rodopi, 1989), II. pp. 582-585.

307-375. Versos tachados en 4 y C. Cf. nota al v. 346. 